\title{
A near-miss case of obstetric haemorrhage managed successfully
}

\author{
Meena N. Satia, Shruti Panchbudhe, Manali P. Shilotri*
}

Department of Obstetrics and Gynecology, Seth G.S.M.C and K.E.M Hospital, Mumbai, Maharashtra, India

Received: 25 October 2016

Accepted: 23 November 2016

*Correspondence:

Dr. Manali P. Shilotri,

E-mail: manali.shilotri@gmail.com

Copyright: (c) the author(s), publisher and licensee Medip Academy. This is an open-access article distributed under the terms of the Creative Commons Attribution Non-Commercial License, which permits unrestricted non-commercial use, distribution, and reproduction in any medium, provided the original work is properly cited.

\begin{abstract}
Functioning of health systems with respect to maternal health were previously audited using indicators like maternal mortality ratio. However, maternal morbidity as a consequence of pregnancy-related complications is not accounted for in these indicators. Thus, the World Health Organization (WHO) has formulated a maternal near-miss approach to pregnancy complications for a more thorough evaluation of health care systems across the world. In practical terms, women are said to be maternal near-miss cases when they survive lethal conditions during pregnancy or in the postpartum period. We report one such case of traumatic variety of postpartum haemorrhage subsequent to a lower segment caesarean section with immediate post-operative removal of cervical cerclage threads that resulted in a maternal near-miss case.
\end{abstract}

Keywords: Maternal near-miss, Maternal mortality, Postpartum haemorrhage

\section{INTRODUCTION}

India is still falling short of the target stated in Millennium Development Goal number five which aimed at improving maternal health. Maternal mortality ratio has always been recognised as an important indicator of quality of health services of a country but there are certain grey areas which need attention when maternal mortality audits are undertaken. Pregnant women's health status is not represented by mortality indicators alone; hence the concept of severe acute maternal morbidity (SAMM) was established. Apart from supplementing maternal mortality ratio in mortality audits, SAMM demonstrates that high risk obstetric patients can be triaged by junior doctors in busy obstetric units without compromising standards of care. ${ }^{1,2}$ The WHO has now defined a maternal near miss as a woman who nearly died but survived a complication that occurred during pregnancy, childbirth, or within 42 days of termination of pregnancy. ${ }^{3}$ This concept is superior to maternal death and draws attention to surviving women's reproductive health. The practical implementation of the maternal near-miss approach should help in improving the quality of obstetric care for reducing maternal mortality and improving maternal health. ${ }^{4}$ In 2009 , WHO formulated well-defined criteria for the identification of these cases. These criteria are unique because they consider not only clinical but also laboratory parameters and treatment based criteria. Hence, they incorporate both Mantel's and Waterston's criteria. ${ }^{5,6}$ If any one criteria fails to pick up the case, the other can cover up for it, thus decreasing the chance of missing any case.

\section{CASE REPORT}

A 30 year old Para 2 living 2 presented to our emergency department in a state of hypovolaemic shock 6 hours after an emergency lower segment caesarean section (LSCS) done in a private hospital. On examination, patient was markedly pale; pulse was 160 per minute, systolic blood pressure $60 \mathrm{mmHg}$ on vasopressors, no icterus and pedal oedema. On per abdomen examination uterus was 20 weeks size, well contracted, with evidence of abdominal distension with guarding and tenderness all over the abdomen. On vaginal examination there was minimal bleeding, os was closed, cervical cerclage knots were felt 
posteriorly. Urine output was 50 cc over 6 hours, clear in appearance. She had undergone an emergency LSCS in a private hospital at 32 weeks of gestation for placenta praevia with preterm premature rupture of membranes with a rising trend of complete blood count and Creactive protein (CRP). She was covered with intravenous antibiotics and antenatal steroids. During the caesarean section, baby delivery was difficult as the lower segment was not well formed and hence forceps application was done. She had a history of McDonald's encerclage done at 18 weeks of gestation for short cervix. Removal of the cerclage knots was attempted in the operation theatre, after the caesarean section but the attempt failed as the knots were embedded in the cervix. Intra-operative blood loss was estimated to be $1500 \mathrm{ml}$ and the patient had tachycardia (pulse - 100/min) with hypotension (BP 90/60 $\mathrm{mmHg}$ ). She was given 2 units of packed red cells in the immediate postoperative period in view of the blood loss. However, her hypotension and tachycardia persisted. A dopamine drip was started, 2 more units of whole blood and one unit of fresh frozen plasma were transfused. An abdominal ultrasonography was performed which was suggestive of haemoperitoneum. Despite inotropic support her BP was $70 \mathrm{mmHg}$ systolic; thus in view of deterioration in her clinical parameters she was shifted to our tertiary care centre. In our emergency department, she was intubated and shifted immediately to the operation theatre for exploratory laparotomy SOS obstetric hysterectomy in view of suspected haemoperitoneum with shock. Intraoperatively, there was haemoperitoneum of around 2 litres, uterus was atonic and there were multiple lacerations on the posterior wall of the uterus at the level of uterine incision which were bleeding torrentially; hence the decision for obstetric hysterectomy was taken. (Figure 1) Massive haemorrhage from uterine lacerations could have been due to instrumental delivery and difficult extraction of the baby or due to attempted removal of the embedded encerclage knots. Obstetric hysterectomy was uneventful. The patient received 2 units of whole blood intraoperatively and 1 unit postoperatively. Postoperative course was uneventful and she was discharged from the hospital on the $10^{\text {th }}$ postoperative day in good health.

\section{DISCUSSION}

Death of a mother during delivery cripples a family and which as a unit is shattered. ${ }^{7}$ Behind each maternal death there are many more women with pathophysiological conditions who have just escaped death. Hypertensive disorders of pregnancy and haemorrhage usually top the list of causes of near-miss cases. ${ }^{7}$ Infectious diseases are also emerging as an important cause of maternal mortality. Every hurdle can be crossed but that is possible only if one understands the root cause of the problem. Similarly, reducing maternal mortality effectively requires more insight not only in maternal deaths but also in the near-miss cases. All maternal near-miss cases are living lessons, who despite their misery show us our deficiencies. The obstetric near-miss cases can be prevented from becoming maternal deaths only by providing prompt and appropriate medical care. Thus, we need to have systems and protocols to identify these nearmiss cases and immediately institute the necessary measures to help save maternal lives.

Table 1: WHO inclusion criteria for baseline assessment of quality of care.

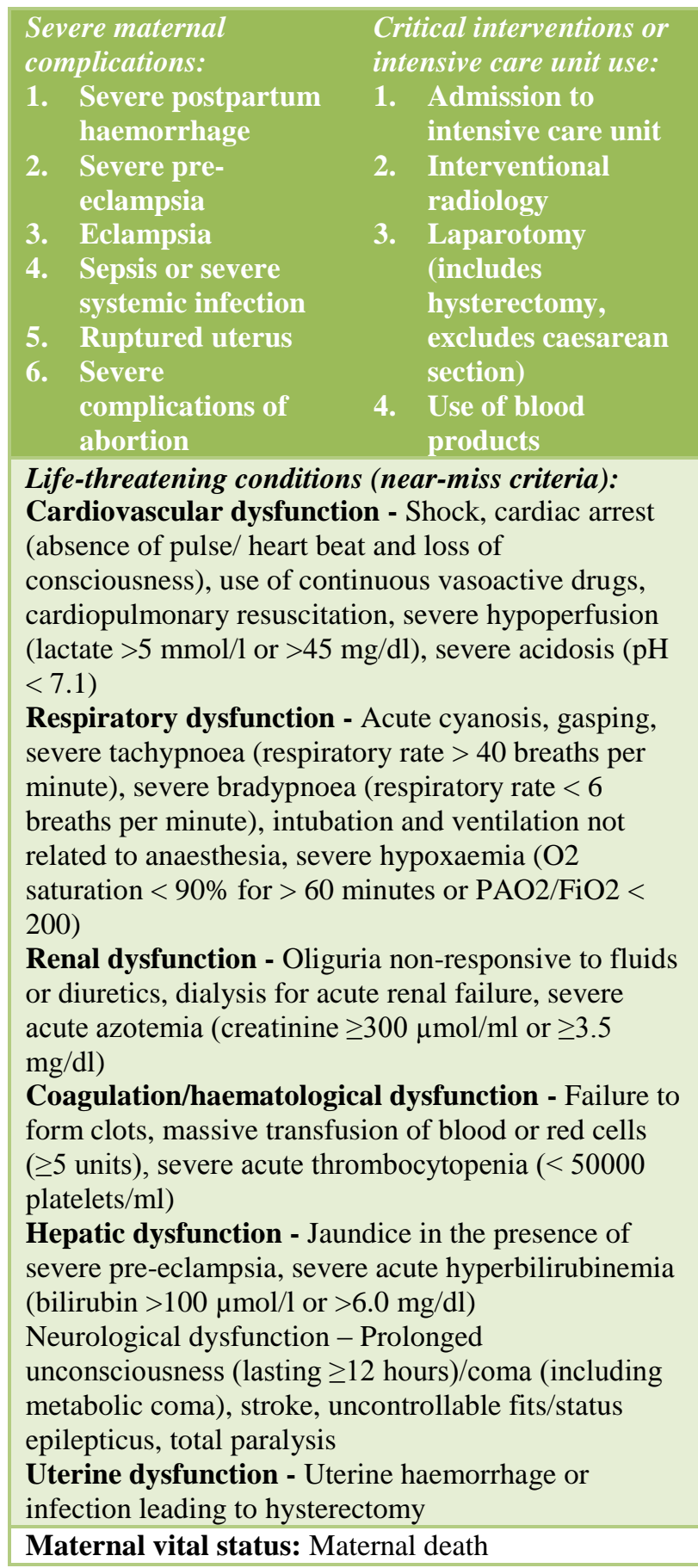

The WHO near-miss approach is implemented in three steps: (1) baseline assessment (or reassessment); (2) Situation analysis and (3) interventions for improving health care. Identification of eligible women is of utmost importance for the success of this approach. Table 1 
describes the inclusion criteria laid down by the WHO to be included as near-miss cases. Our patient, as described above, fulfilled the WHO inclusion crieteria i.e. she had cardiovascular system involvement in the form of shock requiring vasoactive drugs, respiratory system involvement in the form of tachypnoea and was not maintaining $\mathrm{O} 2$ saturation and had uterine dysfunction in the form of haemorrhage.

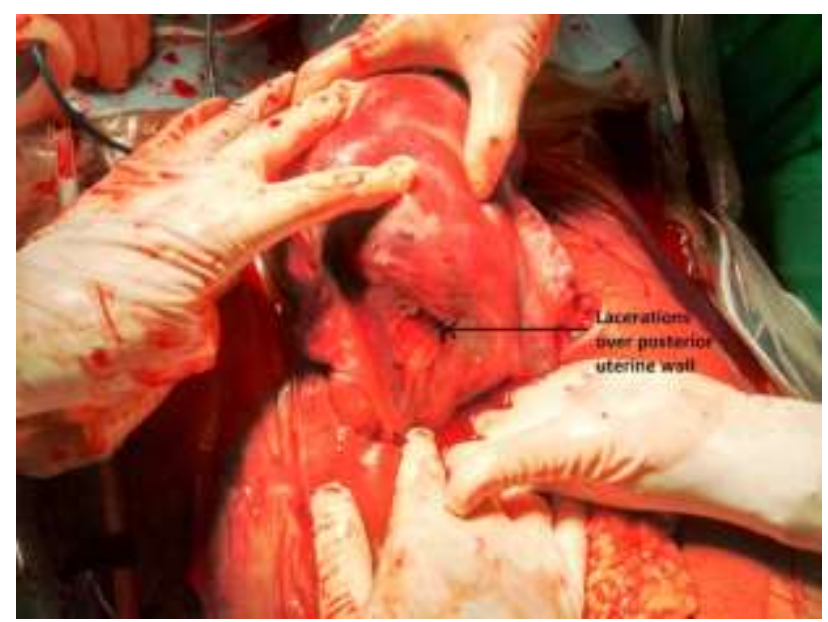

Figure 1: Intraoperative findings showing lacerations over posterior uterine wall in the lower segment.

A five-factor scoring system has been described by Geller et al. for recognition of near miss cases, which has a sensitivity of almost $100 \%$ and a specificity of $93.9 \%{ }^{8}$ It comprises of organ-system failure, intensive care unit admission, blood transfusions of more than 3 units, intubation for $>12$ hours and surgical intervention (hysterectomy/re-laparotomy). Each of these factors is given a score in descending order from 5, 4, 3, 2 and 1 respectively, giving a maximum score of 15 . The cut off for near-miss case is a score of 8 or greater. Our patient had a score of 13 according to the above criteria.

Timely referral to a tertiary care centre, prompt action, availability of good infrastructure with facilities for imaging and the availability of in house skilled surgeons helped to save the life of our patient. Lessons learnt from management of near-miss cases help us identify lacunae in our health care systems and can serve as a beneficial tool in taking corrective measures.

\section{CONCLUSION}

Quality of health care for pregnant women is not reflected by mortality indicators alone, hence the new concept of maternal near-miss cases is coined and should be incorporated in the present health providing system. Delayed diagnosis, late transfers in morbid conditions and lack of infrastructure are often the main causative factors for increase in maternal morbidities and mortalities in developing countries. As analysis of nearmiss cases represents the true quality of health care provided by the nation, it is worth incorporating in the national indices.

Funding: No funding sources

Conflict of interest: None declared

Ethical approval: Not required

\section{REFERENCES}

1. Sivalingam N, Looi KW. Clinical experience with management of "near-miss" cases in obstetrics. Medical Journal of Malaysia. 1999;54(4):496-503.

2. Say L, Pattinson RC, Gülmezoglu AM. WHO systematic review of maternal morbidity and mortality: the prevalence of severe acute maternal morbidity (near miss). Reproductive Health. 2004;1(1):10-9.

3. Pattinson RC, Say L, Souza JP, van den Broek N, Rooney C. WHO maternal death and near-miss classifications. Bull World Health Organ. 2009;87:733804.

4. Say L, Souza JP, Pattinson RC. WHO working group on Maternal Mortality and Morbidity classifications. Maternal near miss-towards a standard tool for monitoring quality of maternal health care. Best Pract Res Clin Obstet Gynaecol. 2009;23(3):287-96.

5. Mantel GD, Buchmann E, Rees H, Pattinson RC. Severe acute maternal morbidity: a pilot study of a definition for a near-miss. British Journal of Obstetrics and Gynaecology. 1998;105(9):985-90.

6. Waterstone $\mathrm{M}$, Wolfe $\mathrm{C}$, Bewley S. Incidence and predictors of severe obstetric morbidity: case-control study. British Medical Journal. 2001;322(7294):108993.

7. Singh A, Shrivastava C, Dube S. Maternal Near Miss: A Valuable Contribution in Maternal Care. The Journal of Obstetrics and Gynecology of India. 2016;66(S1):S217-22.

8. Geller SE, Rosenberg D, Cox S, Brown M, Simonson L, Kilpatrick S. A scoring system identified near-miss maternal morbidity during pregnancy. J Clin Epidemiol. 2004;57:716-2.

Cite this article as: Satia MN, Panchbudhe $S$, Shilotri MP. A near-miss case of obstetric haemorrhage managed successfully. Int J Reprod Contracept Obstet Gynecol 2017;6:348-50. 